\title{
MODELING AND SUPERVISORY CONTROL DESIGN FOR A COMBINED CYCLE POWER PLANT
}

\author{
Salah G. Abokhatwa * and Reza Katebi ${ }^{*}$ \\ *Industrial Control Centre, \\ Department of Electrical and Electronic Engineering, University of Strathclyde, G1 1QE, Glasgow, UK. \\ e.mail: \{r.katebi, salah\}@eee.strath.ac.uk
}

\begin{abstract}
The traditional control strategy based on PID controllers may be unsatisfactory when dealing with processes with large time delay and constraints. This paper presents a supervisory model based constrained predictive controller (MPC) for a combined cycle power plant (CCPP). First, a non-linear dynamic model of CCPP using the laws of physics was proposed. Then, the supervisory control using the linear constrained MPC method was designed to tune the performance of the PID controllers by including output constraints and manipulating the set points. This scheme showed excellent tracking and disturbance rejection results and improved performance compared with a stand-alone PID controller's scheme.
\end{abstract}

\section{KEY WORDS}

Combined cycle power plant, PID Control, Linearization, Supervisory Model Predictive Control.

\section{INTRODUCTION}

During the last decades, the ever-growing demand for electric power, deregulation of power industry and its associated competition and more strict environmental legislation have given rise to increasing interest in Combined Cycle Power Plants (CCPP) due to their high efficiencies and their low emission. CCPP or combined cycle gas turbine (CCGT) is a power plant system in which two types of turbines, namely a gas turbine and a steam turbine, are combined in one cycle to generate electricity as shown in Fig.1. The purpose of introducing Combined Cycle in power plants is to reduce losses of energy. Their main role lies in the utilization of waste heat, which may be found in exhaust gases from the gas turbine to produce additional electricity.

The power plant is a highly complex, nonlinear, and time varying system. The well known control strategies, based on PID regulatory controllers, have been developed and implemented in power plant systems due to their simplicity to minimize costs. However, to improve the economic operation through constrained optimisation, an advanced control strategy is needed to reduce the operational costs further. Model based predictive control (MPC) has received wide acceptance in process industries because of its ability to handle constraints and its optimization based formulation [1].

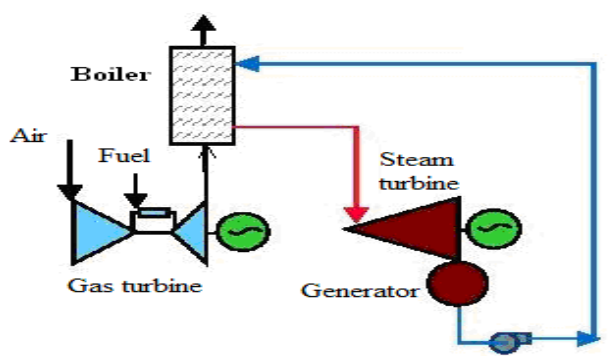

Fig.1. Combined cycle power plant

MPC methods may be divided into two main categories: linear model predictive control (LMPC) and nonlinear model predictive control (NMPC) techniques. LMPC refers to a family of MPC schemes in which linear or linearized models are used to predict the system dynamics. LMPC is acceptable when the process operates at a single operating point and the controller is used only for disturbances rejection. Nonlinear Model Predictive Control (NMPC) techniques involve solving nonlinear differential equations and a nonlinear dynamic optimization problem online. This computational effort is one of the main obstacles to the adoption of non linear predictive controller in a wider context. In addition, using a nonlinear model changes the control problem from a convex Quadratic Program QP to a non-convex NonLinear Program, for which global optimum solution cannot be guaranteed. This has motivated the study of alternative MPC approaches, requiring the solution of simpler optimization problems in real-time. Most of these approaches are based on linear time-varying (LTV) prediction through local Jacobian linearization [2], state dependent description of the nonlinear system [3], or multiple-model approach using gain scheduling method.

In power plant applications model based predictive controllers (MPC) are usually implemented using the supervisory control strategy. The application of this 
strategy to control CCPP has been widely presented and discussed in literature, [4], [5]. In this strategy the MPC provides the regulatory level optimum set-points, based on the objective function dynamic optimisation.

To apply MPC it is required to develop a moderately complex non-linear model that can capture the key dynamical properties over a wide operating range. There are three types of models that have been used for calculating the predicted outputs in MPC implementations: First principles models (white-box), Input-output models (black-box), and hybrid first principles empirical model (gray-box). The advantage of first-principle models is that they are globally valid. Therefore, these models are expected to provide better extrapolation accuracy than empirical models, and can be used to predict the process dynamic over a wide range of operations [6].

The CCPP boiler is a key component for generating steam and heat in industrial processing plants as well as to generate electricity. Industrial boilers are highly complex, nonlinear, and time varying systems. The boiler drum water-level control is considered to be a more challenging problem due to shrink and swell non-minimum phase behavior.

In the literature, the boiler models vary between simple ones, for example, [7], [8] and very complex ones [9], [10]. Reference [11] describes a moderately complicated boiler model for CCPP that is suitable for model based control. It consists of the following subsystems: furnace, risers, drum, superheater, reheater and economizer. This model is based mainly on the paper [12] with some extension from the paper [13]. The furnace model was created from [9], [13] and [14]. This model has been widely used for model based control systems for example, [15], [16]. However, it has a drawback that the boiler model cannot capture the boiler Shrink and Swell phenomenon, where bubbles of steam below the water surface level will shrink or swell, causing the level to initially move in the opposite direction to that expected. This phenomenon causes the non-minimum phase behavior of level dynamics.

This paper presents a supervisory MPC technique to improve the control performance of CCPP by providing the optimal set-points for the PID regulatory level. Output constraints are also included in solving the optimization problem. Regarding the CCPP modelling, the boiler model described in [11] is modified to include the shrink and swell dynamics. This model is integrated with Gas and Steam turbines models to create a complete CCPP simulator in Matlab/Simulink environment.

The paper has been organised as follows: Section 2 describes the CCPP model. Regulatory control (PID) of CCPP modules is presented in section 3. Supervisory
MPC control is discussed in Section 4. The Conclusion is in section 5 .

\section{CCPP NONLINEAR MODEL}

The model of each component is briefly described here.

\subsection{Boiler Model}

The complete boiler system consists of economiser, reheater, superheater, furnace, risers and drum as shown in Fig. 2.

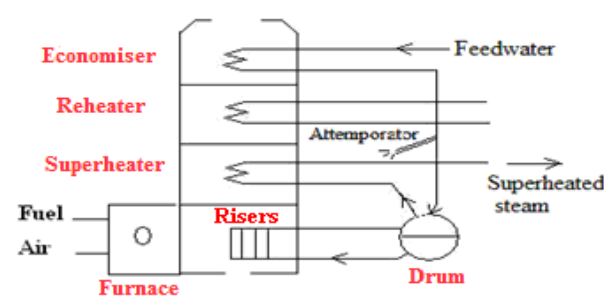

Fig.2. Boiler Model

In this paper, the boiler model described in [11] is modified by replacing the drum and the riser models by a simple fourth order non-linear drum model [17] that can capture much of the system dynamic such as Shrink and Swell phenomena.

The analytical model of the drum system is developed based upon mass and energy balance. The global mass and energy balances are given by:

$$
\begin{aligned}
& \frac{d}{d t}\left[\rho_{s} V_{s t}+\rho_{w} V_{w t}\right]=q_{f}-q_{s} \\
& \begin{array}{r}
\frac{d}{d t}\left[\rho_{s} h_{s} V_{s t}+\rho_{w} h_{w} V_{w t}-\rho V_{t}+m_{t} C_{p} t_{m}\right] \\
=Q+q_{f} h_{f}-q_{s} h_{s}
\end{array}
\end{aligned}
$$

where $V_{s t}$ and $V_{w t}$ represents the total steam and water volumes, respectively. The total volume of the drum, downcomers, and risers is

$V_{t}=V_{s}+V_{w}$

The global energy balance for the riser section is given by

$$
\begin{array}{r}
\frac{d}{d t}\left[\rho_{s} h_{s} \bar{\alpha}_{v} V_{r}+\rho_{w} h_{w}\left(1-\bar{\alpha}_{v}\right) V_{r}-\rho V+m_{r} C_{p} t_{s}\right] \\
=Q+q_{d c} h_{w}-\left(\alpha_{r} h_{c}+h_{w}\right) q_{r}
\end{array}
$$

where $q_{r}$ is the total mass flow rate out of the risers and $q_{d c}$ is the total mass flow rate into the risers. $V_{r}$ represents the riser volume. $\alpha_{r}$ is the steam quality at the riser outlet, $\bar{\alpha}_{v}$ is the average volume fraction. The nominal of the dynamics equation can be summarized as: 


$$
\begin{gathered}
e_{11} \frac{d V_{w t}}{d t}+e_{12} \frac{d p}{d t}=q_{f}-q_{s} \\
e_{21} \frac{d V_{w t}}{d t}+e_{22} \frac{d p}{d t}=Q+q_{f} h_{f}-q_{s} h_{s} \\
e_{32} \frac{d p}{d t}+e_{33} \frac{d \alpha_{r}}{d t}=Q-\alpha_{r} h_{c} q_{d c} \\
e_{42} \frac{d p}{d t}+e_{43} \frac{d \alpha_{r}}{d t}+e_{44} \frac{d V_{s d}}{d t}= \\
\frac{\rho_{s}}{T_{d}}\left(V_{s d}^{0}-V_{s d}\right)+\frac{h_{f}-h_{w}}{h_{c}} q_{f}
\end{gathered}
$$

The model consisted of four states: drum pressure $P$, total water volume $V_{w t}$, steam quality at the riser outlet $\alpha_{r}$ and volume of steam under the liquid level in the $\operatorname{drum} V_{s d}$. $V_{s d}^{0}$ is the volume of steam in drum when there is no condensation. The coefficients $\mathrm{e}_{11}, \mathrm{e}_{12}, \mathrm{e}_{21}, \mathrm{e}_{22}, \mathrm{e}_{32}, \mathrm{e}_{33}$, $\mathrm{e}_{42}, \mathrm{e}_{43}$ and $\mathrm{e}_{44}$ can be obtained from [17] .

The drum level $\ell$ measured from its normal operating level is

$$
\ell=\frac{V_{w d}+V_{s d}}{A_{d}}
$$

The volume of water in the drum is

$V_{w d}=V_{w t}-V_{d c}-\left(1-\bar{\alpha}_{v}\right) V_{r}$

The simulation is carried out based on approximation of steam tables with quadratic functions as follows [18].

$$
\begin{aligned}
& h_{s}=a_{01}+\left(a_{11}+a_{21}(p-10)\right)(p-10) \\
& \rho_{s}=a_{02}+\left(a_{12}+a_{22}(p-10)\right)(p-10) \\
& h_{w}=a_{03}+\left(a_{13}+a_{23}(p-10)\right)(p-10) \\
& \rho_{w}=a_{04}+\left(a_{14}+a_{24}(p-10)\right)(p-10) \\
& t_{s}=a_{05}+\left(a_{15}+a_{25}(p-10)\right)(p-10) \\
& h_{c}=h_{s}-h_{w} \\
& \frac{\partial h_{s}}{\partial p}=a_{11}+2 a_{21}(p-10), \quad \frac{\partial \rho_{s}}{\partial p}=a_{12}+2 a_{22}(p-10) \\
& \frac{\partial h_{w}}{\partial p}=a_{13}+2 a_{23}(p-10), \quad \frac{\partial \rho_{w}}{\partial p}=a_{14}+2 a_{24}(p-10) \\
& \frac{\partial t_{s}}{\partial p}=a_{15}+2 a_{25}(p-10)
\end{aligned}
$$

where:

$$
\begin{aligned}
& a_{01}=2.728 \times 10^{6}, \quad a_{11}=1.792 \times 10,{ }^{4} a_{21}=-924.0, \quad a_{02}=55.43 \\
& a_{12}=7.136, \quad a_{22}=0.224, \quad a_{03}=1.408 \times 10^{6}, \quad a_{13}=4.565 \times 10^{4}
\end{aligned}
$$

$$
\begin{aligned}
& a_{23}=-1010.0, \quad a_{04}=691.35, \quad a_{14}=-1.867, \quad a_{24}=0.081 \\
& a_{05}=311.0, \quad a_{15}=7.822, \quad a_{25}=-0.32,
\end{aligned}
$$

In this paper, the drum model was simulated using Skegton power plant data as presented in [11]. Due to lack of data availability, some parameters $\left(V_{s d}^{0}, T\right.$ and $\left.K\right)$ were assumed by scaling down the values from [17]. The total drum volume is calculated from [11] as follows:

$$
V_{d}=\frac{m_{-} d l}{\rho_{w}}
$$

where $m_{-} d l$ and $\rho_{w}$ represents the total drum liquid mass and the drum water density, respectively. The steam quality $\alpha_{r}$ is obtained by solving the following two nonlinear equilibrium equations using the fsolve Matalb function.

$$
\begin{aligned}
& Q=\alpha_{r} h_{c} \sqrt{\frac{2 \rho_{w} A_{d c}\left(\rho_{w}-\rho_{s}\right) g \bar{\alpha}_{v} V_{r}}{k}} \\
& \bar{\alpha}_{v}=\frac{\rho_{w}}{\rho_{w}-\rho_{s}}\left(1-\frac{\rho_{s}}{\left(\rho_{w}-\rho_{s}\right) \alpha_{r}} \ln \left(1+\frac{\rho_{w}-\rho_{s}}{\rho_{s}} \alpha_{r}\right)\right)
\end{aligned}
$$

The steam volume in the drum is calculated as follows:

$$
V_{s d}=V_{s d}^{0}-\frac{T_{d}\left(h_{w}-h_{f}\right)}{\rho_{s} h_{c}} q_{f}
$$

Parameters and the calculated equilibrium values used in the simulation are listed in Table 1 and Table 2.

Table 1. Boiler parameters

\begin{tabular}{|c|c|l|c|}
\hline Parameter & value & \multicolumn{1}{|c|}{ Parameter } & Value \\
\hline Total metal mass $m_{t}$ & $45,000 \mathrm{~kg}$ & Drum mass $m_{d}$ & $15,000 \mathrm{~kg}$ \\
\hline Riser metal mass $m_{r}$ & $22,500 \mathrm{~kg}$ & Riser volume $V_{r}$ & $6.53 \mathrm{~m}^{3}$ \\
\hline Residence time $T_{d}$ & $2.93 \mathrm{~s}$ & Drum volume $V_{d}$ & $9.25 \mathrm{~m}^{3}$ \\
\hline Friction coefficient $k$ & 2.98 & Area of drum $A_{d}$ & $1.17 \mathrm{~m}^{2}$ \\
\hline$\beta$ & 0.3 & Area -downcomer & $0.1 \mathrm{~m}^{2}$ \\
\hline $\mathrm{V}_{\text {sd }}^{0}$ & $1.572 \mathrm{~m}^{3}$ & Downcomer vol. $\mathrm{V}_{\mathrm{dc}}$ & $2.1 \mathrm{~m}^{3}$ \\
\hline
\end{tabular}

Table 2. The inputs and initial states for boiler

\begin{tabular}{|l|c|l|c|}
\hline Inputs & value & Initial states & Value \\
\hline Steam flow rate & $12 \mathrm{~kg} / \mathrm{s}$ & Total water volume & $10.87 \mathrm{~m} 3$ \\
\hline Water flow rate & $12 \mathrm{~kg} / \mathrm{s}$ & Drum pressure & $4.5417 \mathrm{Mpa}$ \\
\hline Heating value & $24.48 \mathrm{MW}$ & Steam quality & 0.02334 \\
\hline Feedwater Enthalpy & $5.6105 \mathrm{~kJ} / \mathrm{kg}$ & Steam vol. in drum & $0.9882 \mathrm{~m} 3$ \\
\hline
\end{tabular}

In order to verify the correct behaviour of the simulated model, open loop tests are performed by simulating the response to $3.4 \mathrm{~kg} / \mathrm{s}$ step change in steam flow rate as shown in Fig. 3. The simulation results agreed well with the paper [17] results.

As shown in Fig. 3 the pressure and the water volume both decreased due to the increase in steam. The decrease 
in the pressure also leads to an increase of evaporation rate which in turn leads to decrease in total water volume. The pressure drop also caused the steam quality at riser outlet to increase initially and then it decreased due to the increased steam flow rate. The steam volume in the drum $\left(V_{s d}\right)$ increased slightly due to pressure drop. Finally, the figure show initial increase of drum water level due to Shrink and Swell phenomenon.
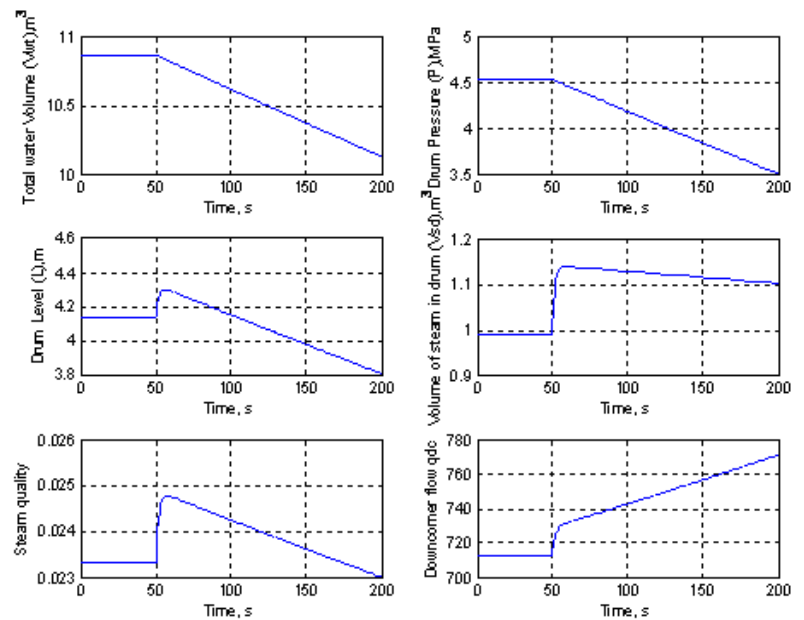

Fig. 3. Response to $3.4 \mathrm{~kg} / \mathrm{s}$ step change in steam flow rate

A comparison between the results of this drum model and Drum and Riser model from [11] using the Skegton power plant data are shown in Fig. 4. The results show the advantage of this model to capture the Shrink and Swell non-minimum phase behavior.
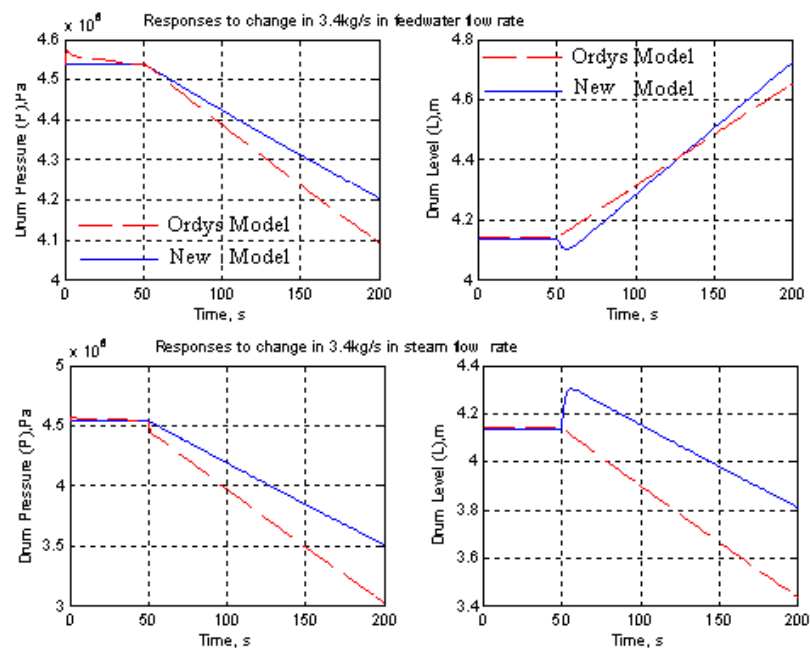

Fig. 4. Comparison between two drum boiler models

To create a complete boiler model, this boiler drum model is integrated with the other boiler subsystems models which are the furnace, economiser, reheater, and superheater as described in [11]. The complete boiler process was represented by $16^{\text {th }}$ order nonlinear model using the Matlab/Simulink S-function. Fig. 5 presents a block diagram of the boiler model that includes the interconnected subsystems.

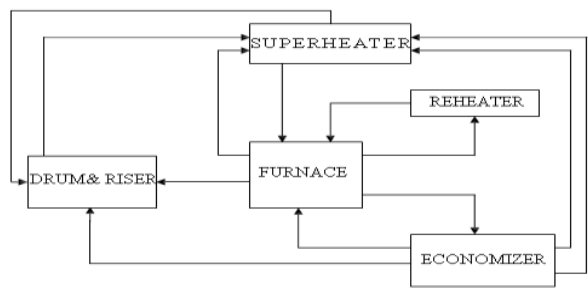

Fig.5. Boiler block diagram

\subsection{Gas Turbine Model}

The Skegton (34 MW output power) gas turbine model based on [19], [20] papers which described in [11] was used to construct S-Function Simulink simulator. The Gas turbine model is divided into four modules as shown in Fig. 6: Fuel system (fuel valve and actuator), Compressor, Combustor and Turbine. This model has been validated using real data [5].

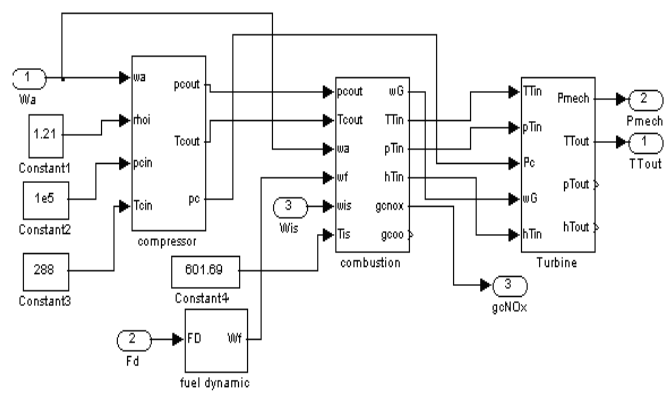

Fig.6. Gas turbine model

\subsection{Electrical Generator Model}

In this study, a simple generator model was used which includes only the real power and frequency variation as follows [11]:

$$
\frac{d \omega}{d t}=\frac{\omega_{0}}{2 H}\left[P_{m e c h}-P_{e}-D\left(\omega-\omega_{0}\right)\right]
$$

where $\omega$ is the frequency of the generator. $\mathrm{H}$ is the inertia constant. D is the damping coefficient. $\omega_{0}$ represents the synchronous frequency.

\subsection{Steam Turbine Model}

The steam turbine model equations are adopted from [11]. These equations are programmed using MATLAB S-Function and simulated with the Reheater module. Fig. 7 shows the complete steam turbine model including the boiler Reheater model. 


\section{CCPP PID REGULATORY CONTROL}

The main purpose of the regulatory control layer is to keep the plant in safe and stable operation, by keeping the controlled variable at or close to their set-points.

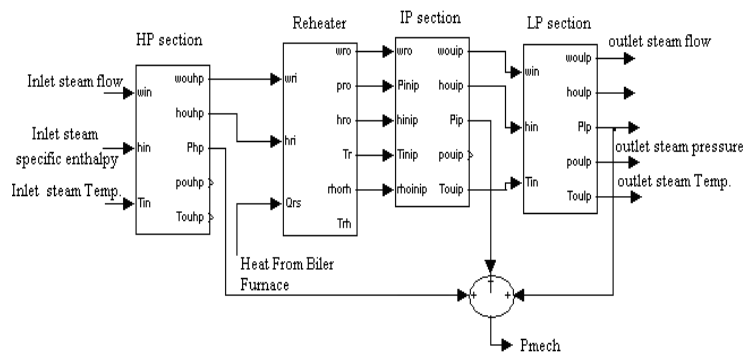

Fig.7. Steam Turbine Model

\subsection{Boiler Control Scheme}

The boiler control system consists of four simple proportional integral (PI) control loops designed to meet the set-points requirements as shown in Fig. 8. They are: adjusting the induced draught fan speed to control the air pressure in furnace, regulating a feed-water supply to maintain the drum water level, adjusting the superheat spray water flow to control the superheat steam temperature, adjusting the fuel supply to the boiler to control the superheated steam pressure.

\subsection{Gas Turbine control Scheme}

The gas turbine control scheme is adopted from [11], [19] and [5]. In this scheme, the main control loop is the speed governor. It detects frequency deviation from the nominal value and determines the controlled variable (Fuel demand $F_{d}$ ). The speed governor loop sharing its controlled variable $\left(\mathrm{F}_{\mathrm{d}}\right)$ with a temperature controller and the power controller. These three different controllers outputs are compared into a low value select function (LVS), which select the minimum of three incoming signals as shown in Fig. 9. The fuel demand signal is then fed to the gas turbine model through the fuel dynamic model.

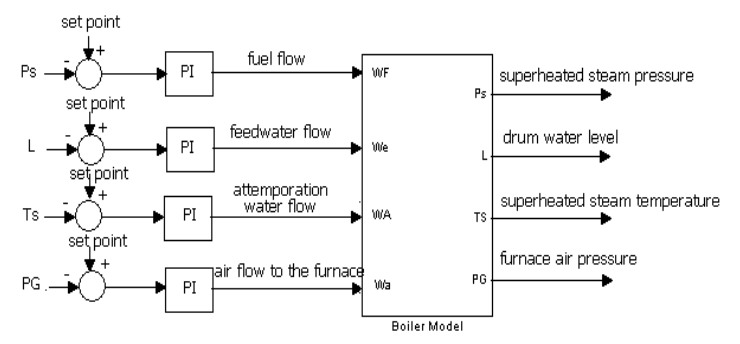

Fig.8. Boiler control system

The temperature control consists of two branches. The main branch is a proportional- integral (PI) controller, which acts as air supply control. The second branch is a proportional controller, which acts as fuel demand controller through the LVS minimum value function. It's used to control the exhaust temperature when the main controller is not enough to maintain safe temperatures. A proportional-integral (PI) controller is used to control the injected steam flow into the combustion chamber $\left(\mathrm{w}_{\mathrm{is}}\right)$ to control gas turbine NOx emission rates.

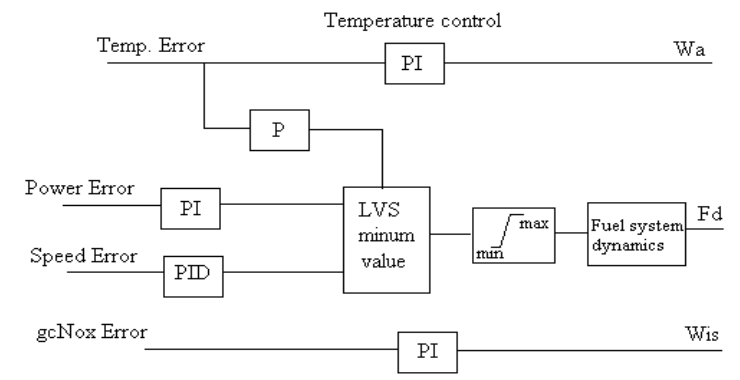

Fig.9. Simplified representation of Gas turbine control scheme

\subsection{Steam Turbine Control Scheme}

The steam turbine control scheme used in this paper is based on boiler following mode as in [21]. As shown in Fig. 10, the steam flow from the boiler is regulated by a PID controller to meet the load demand. The steam pressure and temperature are controlled in the boiler system.

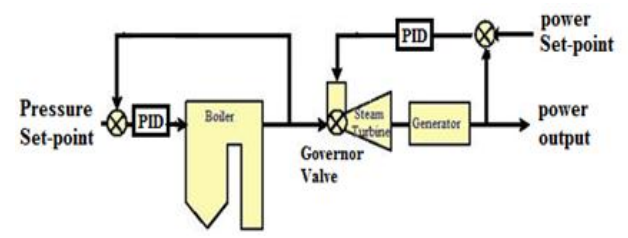

Fig.10. Boiler Follower mode

\subsection{Simulation of the Complete CCPP System}

CCPP are implemented in MATLAB/Simulink Sfunctions which provide an efficient algorithm for integration. The hierarchical structure of CCPP consists of three subsystems: boiler, gas turbine with generator, and steam turbine with generator. In this study, the controlled variables of the complete CCPP system are chosen as: boiler superheated pressure (Ps), boiler drum level (L), boiler superheated temperature (Ts), furnace gas pressure $\left(\mathrm{P}_{\mathrm{G}}\right)$, gas turbine exhaust temperature $\left(\mathrm{T}_{\text {Gout }}\right)$, power of gas turbine $\left(\mathrm{P}_{\mathrm{mG}}\right)$, NOx level in gas turbine exhaust gases $\left(\mathrm{g}_{\mathrm{NOx}}\right)$, and power of steam turbine $\left(\mathrm{P}_{\mathrm{ms}}\right)$.

\subsubsection{PID Tuning}

Control of power plants is usually organised in a hierarchy levels. The PID set points are manipulated using model-based predictive control to achieve a better performance. Hence PIDs are mainly used to regulate the systems and MPC is used to improve tracking and minimise an economic performance index.

The multi-loop systems are usually tuned by tuning each single-loop PID controller sequentially. However, when 
loops interaction is inevitable, this method is not effective since tuning a loop may detune other loops in the system. In addition, some sequential tuning methods are only applicable to open loop stable system. For this reason, extensive effort has been focused on how to effectively take into account loop interactions in designing multiloop PI/PID controllers. Most tuning methods described in the literature can mainly be classified under two groups as follows [22]: the parametric and non-parametric model methods. In the parametric methods, a linear model of the process is required either in transfer matrix or state space model. These methods are more suitable for off-line PID tuning. The best-known method of this type is the biggest log-modulus tuning (BLT) method [23]. In this type, there are also: the internal model control method (IMC) [24], the Gain and phase margin method and the optimal control based methods. The non-parametric methods are based on using only partial modelling information, usually obtained from plant step tests or frequency responses. Therefore, they are preferred by the plant operators and more suitable for on-line applications. Linear models, if they are available can also be used to improve the control design.

Among the most common non-parametric PID tuning methods there are : Davison method [25], PenttinenKoivo method [26] , Maciejowski method [27] and the combined method proposed by [28] that combines ideas from the three methods.

In this paper, the best values for the PID gains are found using the above multivariable non-parametric PID tuning methods as described in [29].

\section{4- SUPERVISORY MPC CONTROL FOR CCPP}

The proposed hierarchical structure control strategy consists of two levels, a conventional PID level and a supervisory MPC optimization level as shown in Fig. 11.

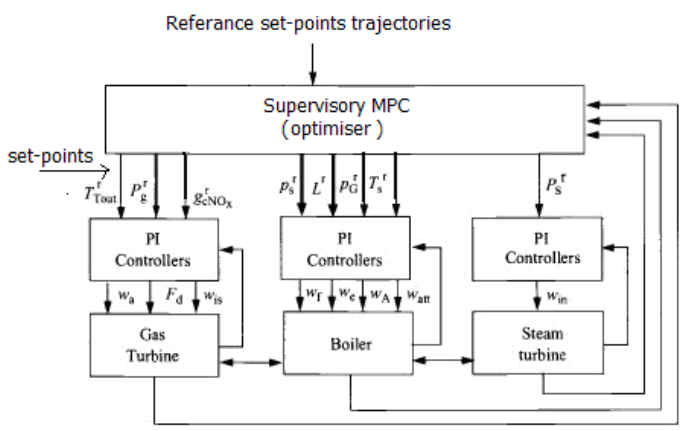

Fig.11. Supervisory MPC

\subsection{Linearization of CCPP system}

In this paper, the nonlinear model of CCPP including the PI controllers was linearized into state space model in a given operating point using Simulink Control Design program. In this simulation, it was assumed that the load operating points are $80 \%, 90 \%, 110 \%$ and $120 \%$ of the nominal operating $\left(\mathrm{Ps}=4.525 \times 10^{6} \mathrm{pa}, \mathrm{L}=4.142 \mathrm{~m}\right.$, Ts=
$655 \mathrm{~K}, \mathrm{P}_{\mathrm{G}}=1.01 \times 10^{5} \mathrm{pa}, \mathrm{T}_{\mathrm{Gout}}=1018 \mathrm{~K}, \mathrm{P}_{\mathrm{mG}}=0.8 \mathrm{pu}$, $\mathrm{g}_{\mathrm{NOx}}=90.76 \mathrm{ppm}$ and $\left.\mathrm{P}_{\mathrm{ms}}=0.8 \mathrm{pu}\right)$. The linearization results are validated by comparing the simulation outputs of the linear models and the nonlinear model using the same step input. The linearized model obtained was reduced to an acceptable 30th order model using MINREAL and (MODRED) Matlab functions.

\subsection{MPC Formulation}

The MPC formulation used in this paper is based on [30].

The linearized, discrete-time, state-space model:

$$
\begin{aligned}
& x(k+1)=A x(k)+B u(k)+\omega(k) \\
& y(k)=C x(k)+v(k)
\end{aligned}
$$

where, the state noise $\omega(k)$ and measurement noise $v(k)$ are assumed to be Gaussian with zero mean . Based on the state space model (A, B, C), the future values of the plant states and outputs over the prediction horizon may be obtained sequentially as follows [30].

$$
\hat{Y}=\Lambda \hat{x}\left(k_{i}\right)+\Phi U
$$

where: $\Lambda$ and $\Phi$ are the prediction matrices.

The general aim of the control law is that the future output $(\hat{Y})$ on the considered horizon should follow a determined reference signal $(r)$ and, at the same time, the control effort $(u)$ necessary for doing so should be penalized. The cost function to be minimised is of the following quadratic form:

$$
\begin{aligned}
J\left(\hat{x}_{k+1 \mid k}, U_{k}\right)= & \frac{1}{2} \sum_{j=1}^{N_{p}}\left\|\hat{y}_{k+j \mid k}-r_{k+j}\right\|_{Q}^{2} \\
& +\left\|u_{k+j \mid k}-u_{k+j-1 \mid k}\right\|_{S}^{2}
\end{aligned}
$$

where: $N_{p}$ is the maximum output horizon, $\mathrm{Q}$ and $\mathrm{S}$ are the weighting on the tracking error and the control increments respectively. The objective function was represented in vector form as in paper [30]. In this form, the terminal weighting obtained from solving the algebraic Riccati equation can be added to guarantee the closed loop stability.

The objective function can be expressed as:

$$
J\left(\hat{x}_{k+1 \mid k}, U_{k}\right)=\frac{1}{2} U_{k}^{T} H U_{k}+U_{k}^{T} f
$$

Where: $H=\Phi^{T} \bar{Q} \Phi+\bar{S}, \quad \Gamma=\left[\begin{array}{ll}\Phi^{T} \bar{Q} \Lambda & -\Phi^{T} \bar{Q}\end{array}\right]$,

$$
f=\Gamma\left[\begin{array}{c}
\hat{x}_{k+1 \mid k} \\
R_{k}
\end{array}\right]-\left[\begin{array}{c}
S u_{k} \\
0 \\
\cdot \\
0
\end{array}\right]
$$

$\bar{Q}, \bar{S}$ : are diagonal matrices functions of $Q$ and $S$ respectively. 
In this paper, the disturbance rejection was done by augmenting the processes model to include constant step output disturbances. The augmented state-space system can be represented as follows [1]:

$$
\begin{aligned}
& {\left[\begin{array}{l}
x_{k+1} \\
d_{k+1}
\end{array}\right]=\left[\begin{array}{ll}
A & 0 \\
0 & I
\end{array}\right]\left[\begin{array}{l}
x_{k} \\
d_{k}
\end{array}\right]+\left[\begin{array}{l}
B \\
0
\end{array}\right] u_{k}+\left[\begin{array}{l}
\omega_{k} \\
\omega_{k}
\end{array}\right]} \\
& y_{k}=\left[\begin{array}{ll}
C & I
\end{array}\right]\left[\begin{array}{l}
x_{k} \\
d_{k}
\end{array}\right]+v_{k}
\end{aligned}
$$

Constraints are present in all real-world processes. The process variables should stay within specified boundaries, due to design requirements, physical constraints and safety requirements. There are three types of constraints namely, Input constraints, output constraints and state constraints. In this paper, the optimization problem is assumed to be subject to constraints on the plant outputs. The model predictive control in the presence of hard constraints is proposed as finding the parameter vector $U_{k}$ that minimizes the objective function Subject to the inequality constraints [1]:

$$
\begin{aligned}
A U_{k} & \leq B \\
A & =\left[\begin{array}{c}
-\Phi \\
\Phi
\end{array}\right], B=\left[\begin{array}{c}
-Y_{\min }+\Lambda \hat{x}(k) \\
Y_{\max }-\Lambda \hat{x}(k)
\end{array}\right]
\end{aligned}
$$

In order to guarantee the closed loop stability when constraints are presents, a sufficiently large prediction horizon should be selected [30].

\subsection{Simulation and Results}

In this simulation, the nonlinear CCPP states are estimated using Kalman filter, the prediction horizon $\left(N_{p}\right.$ $=80$ ) is selected based on the settling time of the system. The control horizon is assumed to be equal to the prediction horizon. The introduced maximum and minimum output constraints are listed in table 3:

Table 3. Output constraints

\begin{tabular}{|l|c|c|}
\hline \multicolumn{1}{|c|}{ Output constraints } & Minimum & Maximum \\
\hline Superheated boiler pressure (Pa) & $4.44 \times 10^{6}$ & $4.65 \times 10^{6}$ \\
\hline Boiler Drum Level (m) & 3.5 & 4.5 \\
\hline Steam turbine power (pu) & 0.62 & 1 \\
\hline
\end{tabular}

Fig. 12 shows the responses of the boiler drum level and steam turbine power to $+10 \%$ step changes in boiler superheated pressure using constrained and unconstrained MPC. It can be observed that the imposed output constrained are satisfied using the constrained MPC. Simulation results comparing the performance of supervisory MPC and the classical PID controllers are shown in Fig. 13 and Fig. 14. These figures show that MPC is able to reach the setpoint faster than the PID which is continuously oscillates around the setpoint with a larger overshoot. Fig. 13 also demonstrates how the constrained MPC keeps the output pressure level within the specified bounds, which is violated when using the PID controller.

\section{CONCLUSION}

In this paper, it was proposed to use a second layer of control based on MPC to tune the performance of PID controllers. This has the advantage of including output constraints to provide safety limitations and satisfy environmental regulations. Simulation results showed that the supervisory MPC has better performance than the classical PID control schemes and allows taking in account constraints. A comprehensive nonlinear boiler model was also proposed. This model can capture much of the system dynamic.

\section{REFERENCES}

[1] J. M. Maciejowski, Predictive control with constraints: Prentice Hall, 2002.

[2] G. Prasad, G. Irwin, E. Swidenbank, and B. Hogg, "A hierarchical physical model-based approach to predictive control of a thermal power plant for ef' cient plant-wide disturbance rejection," Transactions of the Institute of Measurement and Control, vol. 24, pp. 107-128, 2002.

[3] A. Ordys and M. Grimble, "Predictive control design for systems with the state dependent non-linearities," 2001.

[4] M. Katebi and M. Johnson, "Predictive control design for large-scale systems," Automatica, vol. 33, pp. 421-425, 1997.

[5] D. Saez, F. Milla, and L. S. Vargas, "Fuzzy predictive supervisory control based on genetic algorithms for gas turbines of combined cycle power plants," Energy Conversion, IEEE Transactions on, vol. 22, pp. 689-696, 2007.

[6] J. H. Lee, "Modeling and Identification for NonlinearModel Predictive Control: Requirements, Current Status and Future Research Needs," Nonlinear model predictive control, pp. 269-293, 2000.

[7] F. De Mello, "Boiler models for system dynamic performance studies," Power Systems, IEEE Transactions on, vol. 6, pp. 66-74, 1991.

[8] K. J. Astrom and R. D. Bell, "Simple drum-boiler models," presented at the IFAC international symposium on power systems modelling and control applications., Brussels, Belgium., 1988.

[9] T. Busi and R. Cori, "Parameter identification of a drum boiler power plant," presented at the Power Plant Dynamics, Control andTesting Symposium, Knoxville., 1977.

[10] J. P. McDonald and H. Kwatny, "A Mathematical Model for Reheat Boiler Turbine-generator Systems," 1970, pp. 25-30.

[11] A. W. Ordys, A. W. Pike, M. A. Johnson, R. M. Katebi, and M. J. Grimble, Modelling and simulation of power generation plants: Springer Verlag, 1994.

[12] K. Chien, E. Ergin, C. Ling, and A. Lee, "Dynamic analysis of a boiler," Trans. ASME, vol. 80, pp. 1719-1809, 1958. 
[13] H. Nicholson, "Dynamic optimisation of a boiler," Electronics and Power, vol. 10, pp. 384-385, 1964.

[14] J. M. Rhine, R. J. Tucker, and B. Gas, Modelling of gasfired furnaces and boilers and other industrial heating processes: British Gas, 1991.

[15] D. Saez, A. Ordys, and M. Grimble, "Design of a supervisory predictive controller and its application to thermal power plants," Optimal Control Applications and Methods, vol. 26, pp. 169-198, 2005.

[16] N. A. Harish, R. Ismail, and T. Ahmad, "Transformation of fuzzy state space model of a boiler system: a graph theoretic approach," WSEAS Transactions on Mathematics, vol. 9, pp. 669-678, 2010.

[17] K. J. Åström and R. D. Bell, "Drum-boiler dynamics," Automatica, vol. 36, pp. 363-378, 2000.

[18] K. Mrunalini, P. Kundu, and K. Dutta, "State Space Model for Drum Boiler System," Journal Institution of Engineers India Part El Electrical Engineering Division vol. 86, p. 260, 2006.

[19] I. Rowen, "Simplified mathematical representations of heavy-duty gas turbines," Journal of engineering for power, vol. 105, pp. 865-869, 1983.

[20] A. Hussain and H. Seifi, "Dynamic modelling of a single shaft gas turbine " in IFAC symposium on control of power plants and power systems, Munich, 1992.

[21] D. Sáez, R. Zúniga, and A. Cipriano, "Adaptive hybrid predictive control for a combined cycle power plant optimization," International Journal of Adaptive Control and Signal Processing, vol. 22, pp. 198-220, 2008.

[22] M. Katebi, A. Moradi, and M. Johnson, "Controller tuning methods for industrial boilers," 2000, pp. 1457-1462 vol. 2.

[23] W. L. Luyben, "Simple method for tuning SISO controllers in multivariable systems," Industrial \& Engineering Chemistry Process Design and Development, vol. 25, pp. 654-660, 1986.

[24] C. E. Garcia and M. Morari, "Internal model control. A unifying review and some new results," Industrial \& Engineering Chemistry Process Design and Development, vol. 21, pp. 308-323, 1982.

[25] E. Davison, "Multivariable tuning regulators: the feedforward and robust control of a general servomechanism problem," Automatic Control, IEEE Transactions on, vol. 21, pp. 35-47, 1976.

[26] J. Penttinen and H. Koivo, "Multivariable tuning regulators for unknown systems," Automatica, vol. 16, pp. 393-398, 1980.

[27] J. M. Maciejowski, "Multivariable feedback design," Electronic Systems Engineering Series, Wokingham, England: Addison-Wesley,| c1989, vol. 1, 1989.

[28] P. Martin, I. Yamamoto, M. Katebi, and M. Grimble, "Multivariable PI Tuning in Dynamic Position Control of Ships.," in Proceedings of the 5th IFAC Conference on Manoeuvrin and Control of Marine Craft., Aalborg, Denmark., 2002.

[29] J. Q. Gil, "Multivariable PID Tuning for Power boilerturbine unit," Msc, Electronic and Electrical Eng., University of Strathclyde, Glasgow, 2010.

[30] A. G. Wills, D. Bates, A. J. Fleming, B. Ninness, and S. O. R. Moheimani, "Model predictive control applied to constraint handling in active noise and vibration control," control Systems Technology, IEEE Transactions on, vol. 16, pp. 3-12, 2008.
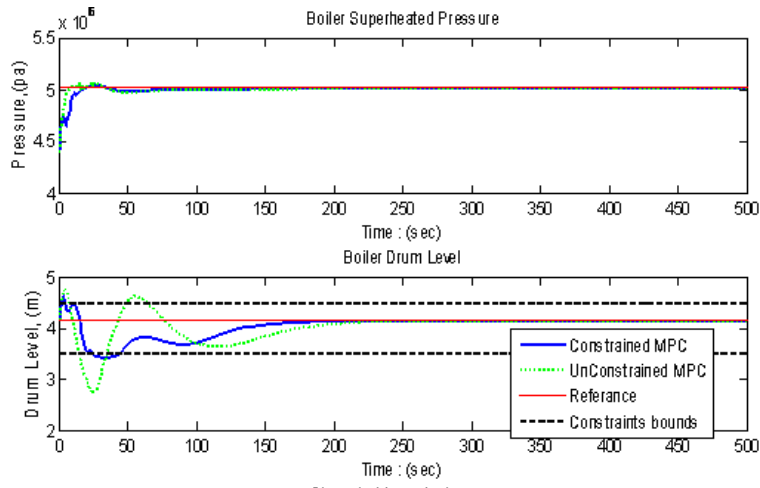

Steam turbine output pawer

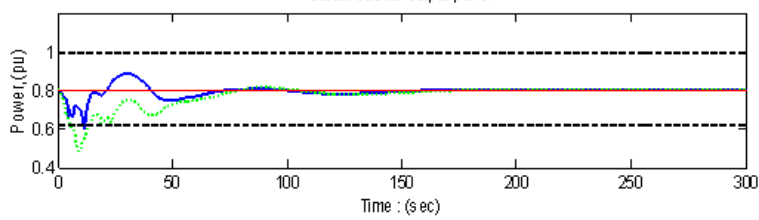

Fig.12. Boiler drum level and power of steam turbine response using constrained and unconstrained MPC
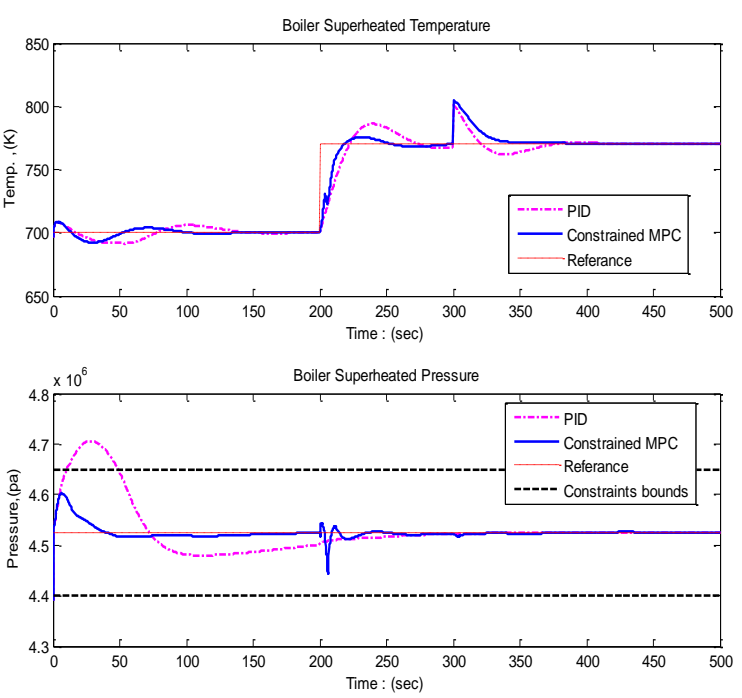

Fig.13. Boiler pressure response to $+10 \%$ setpoint changes and 5\% disturbance at $300 \mathrm{sec}$ in boiler.
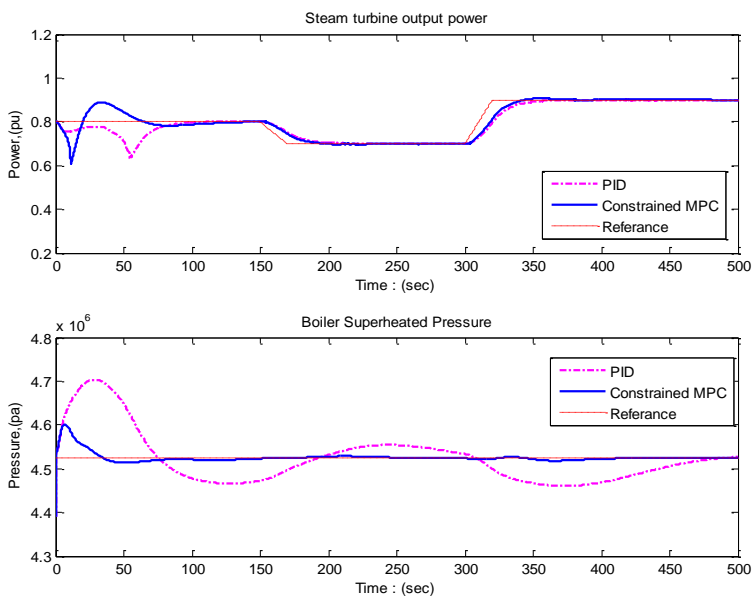

Fig.14. Boiler pressure response to steam turbine load change. 